\title{
Carbohydrate metabolism in exercising horses
}

\section{E Jose-Cunilleras* and KW Hinchcliff}

Exercise Physiology Laboratory, Department of Veterinary Clinical Sciences, The Ohio State University, Columbus, OH 43210, USA

*Corresponding author: jose-cunilleras.1@osu.edu

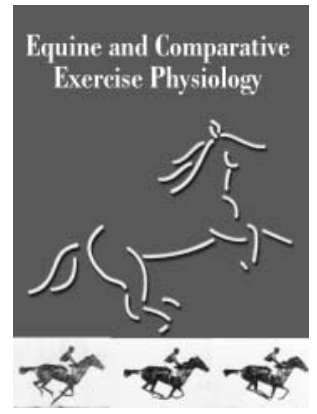

Submitted 23 November 2002: Accepted 3 March 2003

Review Article

\begin{abstract}
Carbohydrate and fat are the predominant sources of energy during exercise in mammals. Carbohydrates, such as muscle glycogen and plasma glucose, and fats from adipose tissue and intramuscular triglycerides are oxidized during exercise in amounts and proportions that vary depending on the exercise intensity, level of fitness and nutritional status. In horses, muscle glycogen, and to a lesser extent plasma glucose, are oxidized in substantial amounts during low-, moderate- and high-intensity exercise. Carbohydrate availability to skeletal muscle affects exercise performance in humans, however this relationship is not well outlined in horses. Glucose supplementation by intravenous administration during exercise in horses increases duration of moderate-intensity exercise. However, the effect of glucose supplementation by ingestion of a soluble carbohydrate-rich meal prior to exercise on athletic performance has not been established in horses. Low muscle glycogen concentrations prior to exercise in horses are associated with decreased time to exhaustion at moderate- and high-intensity exercise. Nutritional interventions intended to enhance muscle glycogen resynthesis have proved less successful in horses than in other species. Replenishment of muscle glycogen after strenuous exercise in horses is not complete until 48-72 h after exercise, whereas in humans and laboratory animals it is complete by $24 \mathrm{~h}$. The slower rate of muscle glycogen replenishment after exercise in horses may be related to an inherent lower ability to digest starch and other sources of glucose, a lower ability to synthesize muscle glycogen, or both. The aim of this review is to describe the present understanding of carbohydrate metabolism in the exercising horse, its implications on nutrition and athletic performance, and to contrast it with that in other species.
\end{abstract}

Keywords: exercise; glycogen; glucose; starch; muscle

\section{Introduction}

The athletic horse has a large capacity to perform muscular work compared with many other mammals, including humans. Energy to perform work is obtained from oxidation of carbohydrate and fat and, to a minimal extent, protein. The energy requirements of athletic horses are met by ingestion of these nutrients. However, while metabolism and energy transduction in muscle fibres of mammalian species are similar, the energy requirements of different athletic species are met by ingestion of very different diets.

The horse is a herbivore that has adapted its gastrointestinal function for hindgut fermentation. Unlike ruminants, equids have a small simple stomach, followed by $60-70 \mathrm{ft}(18-22 \mathrm{~m})$ of small intestine where digestion and absorption of soluble carbohydrates, fat and protein occur. Microbial fermentation occurs in the caecum and large colon, which hold
$80-1001$ of liquid and house billions of bacteria and protozoa, with the breaking down of plant fibre releasing volatile fatty acids (VFAs), the most abundant being acetate, propionate and butyrate ${ }^{1}$. Energy intake of horses is primarily from carbohydrates in forages and grains. Fibre in forages is fermented in the hindgut and the VFAs produced used for synthesis of fatty acids, and from propionate, glucose. Starch and sugars in grains and molasses are digested primarily in the small intestine and absorbed as monosaccharides and eventually transformed to glucose or fat.

Glucose is stored as glycogen in liver and muscle. Glycogen is a branched polymer of glucose with a mixture of $\alpha-1,4$ and $\alpha-1,6$ linkages between glucose units. Muscle glycogen constitutes over $90 \%$ of the carbohydrates in the body (Table 1) and the amount of glycogen is muscle fibre type-dependent. Fast-twitch muscle fibres (Type-II) have greater glycogen content 
Table 1 Fuel stores, distribution within the body and energy storage in a $450 \mathrm{~kg}$ horse ${ }^{29}$

\begin{tabular}{llcc}
\hline Fuel & \multicolumn{1}{c}{ Tissue } & Grams & Energy (kcal) \\
\hline Triglycerides & Adipose tissue & 40000 & 360000 \\
Triglycerides & Muscle & $1400-2800$ & $12600-25200$ \\
Glycogen & Muscle & $3150-4095$ & $13230-17200$ \\
Glycogen & Liver & $90-300$ & $380-1260$ \\
Glucose & Plasma & 27 & 110 \\
\hline
\end{tabular}

than slow-twitch muscle fibres ${ }^{2,3}$. Fat is stored in both adipose tissue and in muscle, both at intracellular (myocyte) and extracellular sites. In contrast to carbohydrates, intramyocellular triglycerides make up only $\approx 5 \%$ of the fats in the body. Slow-twitch muscle fibres have greater lipid content than fast-twitch high oxidative muscle fibres, and the amount of lipid in fast-twitch low oxidative muscle fibres is negligible ${ }^{4,5}$. Intracellular triglycerides are seen within muscle fibres as lipid droplets in close proximity to mitochondria.

Differential storage of glycogen and intramyocellular triglycerides among muscle fibre types is related to inherent metabolic differences of the muscle fibres. Muscle fibre types are established based on differences in contractile properties and oxidative/glycolytic enzymatic profiles (slow-twitch, fast-twitch high oxidative and fast-twitch low oxidative), based on differences in $\mathrm{pH}$ sensitivity of the myofibrillar ATPase (Type-I, -IIA and -IIB) and based on myosin heavy-chain (MyHC) expression (Type-I, -IIA and -IIX). Type-I fibres have a MyHC isoform that hydrolyses ATP slowly, resulting in a slow cross-bridge cycle, together with a small cross-sectional area, a high number of capillaries, greater storage of lipids and a high oxidative capacity. However, their glycolytic capacity and glycogen content are lower than that of other fibre types. In contrast, Type-II fibres have MyHC isoforms that create fast cross-bridge cycling and therefore develop force rapidly. Type-IIX fibres are adapted for high power outputs for a limited time because they have a low oxidative capacity and limited oxygen availability (as reflected by their large cross-sectional area and relatively low capillary supply). TypeIIA fibres, however, have a considerable number of both capillaries and mitochondria, and rely on glycolytic and oxidative metabolism; they are therefore able to sustain high power outputs for longer than Type-IIX fibres. Hybrid Type-IIAX fibres are intermediate in their properties ${ }^{6,7}$.

Glucose and fatty acids stored within and outside the muscle are used as fuels during exercise in horses, as well as in other athletic species. However, quantitatively the contributions of different fuels vary among different athletic species due to inherent metabolic and nutritional differences. Our aim is to describe the present understanding of carbohydrate metabolism in the exercising horse, its implications on nutrition and athletic performance, and to contrast it with that in other species.

\section{Energy metabolism and fuel sources during exercise}

During exercise, skeletal muscles perform mechanical work using chemical energy obtained from fat and carbohydrate oxidation. The relative contributions of fat and carbohydrate used to fuel exercise depend on exercise intensity, level of fitness, sex, menstrual phase in the case of women, environmental conditions, type of meal ingested and interval from ingestion to initiation of exercise.

All of these factors influence muscle and liver glycogen concentrations and circulating hormone status (insulin, glucagon, catecholamines) and will dictate the mixture of substrates utilized to fuel exercise. Many, but not all, of these factors have been evaluated in horses.

Intensity of exercise is generally described relative to the percentage of maximal oxygen consumption (\% $\left.\dot{\mathrm{VO}}_{2 \max }\right)$. Increasing exercise intensities shift the predominant substrate contribution to energy expenditure from fat to carbohydrate. In addition, high-intensity exercise increases reliance on intramyocellular stores of carbohydrate (glycogen granules) and fat (triglyceride droplets). Some of the mechanisms that limit fat oxidation with increasing exercise intensities include reduced non-esterified fatty acid mobilization from adipose tissues due to maintained lypolysis but reduced blood flow to adipose tissue ${ }^{8}$, and decreased activity of carnitine palmitoyltransferase I, which is responsible for transport of long-chain fatty acids from the sarcoplasm to the mitochondria, due to decreases in intracellular $\mathrm{pH}^{9}$. The increase in muscle glycogen degradation as exercise intensity increases is related to activation of glycogen phosphorylase, which cleaves a single glucose molecule from glycogen. Increased activity of phosphorylase is in response to increased sarcoplasmic calcium concentration, associated with muscle contractions, and hormonal stimulation by adrenaline-mediated $\beta$-receptors and the intracellular second messenger $3^{\prime}, 5^{\prime}$-cyclic adenosine monophosphate ${ }^{10}$.

Studies performed in trained male and female human athletes demonstrate that increasing exercise intensity from $25 \% \dot{\mathrm{VO}_{2 \max }}$ to $85 \% \dot{\mathrm{V}} \mathrm{O}_{2 \text { max }}$ alters the relative contributions of blood-borne glucose oxidation, muscle glycogenolysis, plasma non-esterified fatty acids (NEFAs) and intramyocellular triglyceride (IMTG) oxidation to energy expenditure ${ }^{11,12}$. At low exercise intensity $\left(25 \% \mathrm{~V}_{2 \max }\right)$ oxidation of plasma NEFAs accounts for most of the energy requirements. At moderate exercise intensity $\left(65 \% \dot{\mathrm{VO}_{2 \max }}\right.$ ) the contribution from oxidation of muscle glycogen, blood-borne glucose and IMTGs is 
greater than at lower exercise intensity. At moderate to high exercise intensity $\left(85 \% \mathrm{VO}_{2 \max }\right)$ the contribution from muscle glycogenolysis increases exponentially and the relative contribution from the rest of the fuels decreases significantly ${ }^{1,12}$. In summary, greater energy fluxes required during high-intensity exercise are met by increased reliance on intramuscular substrate stores, predominantly from muscle glycogen.

\section{Horse studies}

Horses have a higher mass-specific aerobic capacity than humans. Thoroughbred horses have a maximal oxygen consumption $\left(\dot{\mathrm{V}}_{2 \max }\right)$ of approximately $160 \mathrm{ml} \mathrm{O}_{2} \mathrm{~kg}^{-1} \mathrm{~min}^{-1}$ and Olympic-calibre human athletes have a $\dot{\mathrm{V}} \mathrm{O}_{2 \max }$ of approximately $70-80 \mathrm{ml}$ $\mathrm{O}_{2} \mathrm{~kg}^{-1} \min ^{-1}$ (refs 13-15). Similar to pronghorn antelopes, which have a $\dot{\mathrm{VO}}_{2 \max }$ of $\approx 300 \mathrm{ml}$ $\mathrm{O}_{2} \mathrm{~kg}^{-1} \min ^{-1}$ (ref. 16), the high $\dot{\mathrm{VO}}_{2 \max }$ of horses is probably due to the pressure of natural selection on horses to become more athletic and aerobic animals, as well as selective breeding of those horses with greater athletic ability. Horses, when compared with humans, have a greater aerobic capacity because, relative to body mass, the former have a greater oxygencarrying capacity, greater cardiac output and greater oxygen conductance at a capillary level ${ }^{17}$. Other reasons for the apparent greater mass-specific aerobic capacity in horses compared with humans are differences in body composition, the proportion of muscles engaged during running in quadrupeds versus bipeds and differences in muscle mitochondrial density. Muscle mass as a percentage of body weight ranges from $\approx 52 \%$ in Thoroughbred racehorses to $\approx 42 \%$ in average horses of other breeds, and in humans from $\approx 47 \%$ in elite road-cyclists to $\approx 40 \%$ as the average for male young adults ${ }^{18,19}$. Not only is the muscle mass greater in horses than in humans but more importantly the proportion of muscles engaged during exercise in quadrupeds is much greater $(\approx 70-80 \%)$ than in bipeds $(\approx 30-40 \%)$. In addition, mitochondrial density of equine muscle - the volume of mitochondria per volume of muscle fibre - ranges from $6 \%$ to $8.5 \%$ depending on muscle group and fibre type, whereas that of humans ranges from $2 \%$ to $6 \%^{20,21}$. In summary, horses have a high aerobic capacity due to cardiovascular, muscular and metabolic adaptations and to a greater mass of active skeletal muscle relative to body weight.

At the same exercise intensity relative to $\dot{\mathrm{VO}}_{2 \max }$, the mass-specific rates of oxygen consumption $\left(\mathrm{VO}_{2}\right)$ and the energy expenditure are approximately two-fold higher in horses than in humans; in addition higher energy fluxes in horses are associated with greater contribution from carbohydrate oxidation to energy expenditure. Other athletic (i.e. dogs) and non-athletic (i.e. goats) mammals have a similar two-fold difference in mass-specific $\mathrm{VO}_{2}$ and energy expenditure. However, at approximately $60 \% \quad \dot{\mathrm{VO}}_{2 \max }$ the contribution to energy expenditure from carbohydrate (57-60\%) versus fat $(40-43 \%)$ oxidation is similar between dogs and goats, unlike the comparison between horses (75\% from carbohydrate, $25 \%$ from fat) and humans (40\% from carbohydrate, $60 \%$ from fat) ${ }^{11,22,23}$ (Table 2 ).

Horses and dogs, when compared with humans and goats exercising at a similar \% of $\dot{\mathrm{VO}}_{2 \max }$, have a twofold higher energy flux. Horses, when compared with humans, dogs and goats exercising at the same intensity, have a greater proportion of energy derived from carbohydrate. Therefore, observations made in humans or other animals about carbohydrate and fat metabolism and energy requirements during exercise at an apparently similar intensity (same \% $\dot{\mathrm{VO}}_{2 \max }$ ) may not apply to horses.

Estimation of substrate utilization during moderateto high-intensity exercise in horses has limitations not encountered in humans exercising at the same

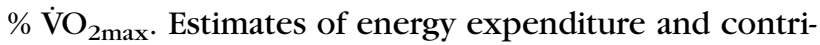
butions from fat and carbohydrate oxidation are obtained using indirect calorimetry and gaseous exchange measurement. Simultaneous infusion of stable isotopes of glucose or fatty acids allows a complete assessment of intramuscular versus extramuscular substrate oxidation. Estimates of whole-body carbohydrate and fat oxidation during exercise by indirect calorimetry are based on some assumptions; one of the assumptions is that the rates of oxygen consumption $\left(\dot{\mathrm{V}}_{2}\right)$ and of carbon dioxide production $\left(\dot{\mathrm{VCO}}_{2}\right)$, as measured in exhaled gas, reflect the consumption of $\mathrm{O}_{2}$ and production of $\mathrm{CO}_{2}$ at a cellular level. However, at high exercise intensities exhaled $\mathrm{CO}_{2}$

Table 2 Mass-specific maximal rates of oxygen consumption $\left(\dot{\mathrm{V}}_{2 m a x}\right)$, as well as rates of oxygen consumption $\left(\dot{\mathrm{V}} \mathrm{O}_{2}\right)$, total energy expenditure (TEE) and contributions from carbohydrate $(\mathrm{CHO})$ and fat oxidation during moderate-intensity exercise in athletic (horses and dogs) and non-athletic mammals (humans and goats) ${ }^{11,22,23}$

\begin{tabular}{|c|c|c|c|c|}
\hline & $\begin{array}{c}\text { Horses } \\
60 \% \dot{\mathrm{VO}}_{2 \max }\end{array}$ & $\begin{array}{c}\text { Humans } \\
65 \% \dot{\mathrm{VO}}_{2 \max }\end{array}$ & $\begin{array}{c}\text { Dogs } \\
60 \% \dot{\mathrm{VO}}_{2 \max }\end{array}$ & $\begin{array}{c}\text { Goats } \\
60 \% \dot{\mathrm{VO}}_{2 \max }\end{array}$ \\
\hline$\dot{V} O_{2 \max }\left(\mathrm{ml} \mathrm{kg}^{-1} \min ^{-1}\right)$ & $\begin{array}{r}137 \\
77\end{array}$ & 67 & $\begin{array}{r}146 \\
84\end{array}$ & $\begin{array}{l}68 \\
39\end{array}$ \\
\hline $\begin{array}{l}\mathrm{VO}_{2}\left(\mathrm{ml} \mathrm{kg}^{-1} \min ^{-1}\right) \\
\text { TEE }\left(\mathrm{cal} \mathrm{kg}^{-1} \mathrm{~min}^{-1}\right)\end{array}$ & $\begin{array}{r}77 \\
400\end{array}$ & $\begin{array}{r}44 \\
200\end{array}$ & $\begin{array}{r}84 \\
410\end{array}$ & $\begin{array}{r}39 \\
190\end{array}$ \\
\hline Contribution from $\mathrm{CHO}$ ox. (\%) & 75 & 40 & 60 & 57 \\
\hline Contribution from fat ox. (\%) & 25 & 60 & 40 & 43 \\
\hline
\end{tabular}


may not accurately reflect gas exchange at a cellular level due to substantial loading of carbon dioxide into the arterial and venous blood and other body fluid compartments, as well as additional carbon dioxide produced from buffering of hydrogen ions by bicarbonate as concentrations of protons increase in muscle and plasma. Therefore, $\dot{\mathrm{V}} \mathrm{CO}_{2}$ as measured by indirect calorimetry at high exercise intensity is an overestimation of the actual production of $\mathrm{CO}_{2}$ at a mitochondrial level, and consequently the estimates of whole-body carbohydrate and fat oxidation are erroneous. Horses running at exercise intensities at or below $60 \% \dot{\mathrm{VO}}_{2 \max }$ have a respiratory exchange ratio $\left(\mathrm{RER}=\dot{\mathrm{V}} \mathrm{CO}_{2} / \mathrm{VO}_{2}\right)$ of 0.90-0.96 and contributions from carbohydrate and fat oxidation can be estimated by indirect calorimetry ${ }^{23,24}$. However, in horses performing an incremental exercise test the RER is above 1 at exercise intensities higher than $75 \% \dot{\mathrm{VO}}_{2 \max }{ }^{25}$. Therefore, indirect calorimetry estimation of contributions from carbohydrate and fat oxidation to energy expenditure cannot be reliably estimated at exercise intensities above 60\% $\dot{\mathrm{V}} \mathrm{O}_{2 \text { max }}$ in horses. Validation of estimates of carbohydrate and fat oxidation by indirect calorimetry during high-intensity exercise requires measurement of the absolute ratios of ${ }^{13} \mathrm{C} /{ }^{12} \mathrm{C}$ in expired air, in endogenous glucose, fat and protein in addition to $\dot{\mathrm{V}} \mathrm{O}_{2}$ to obtain carbohydrate and fat oxidation rates independently of $\mathrm{CO}_{2}$ production ${ }^{26}$. Unlike in horses, measurements of rates of substrate oxidation by indirect calorimetry have been validated in humans exercising up to $85 \% \dot{\mathrm{VO}}_{2 \max }$, an exercise intensity that results in a RER of $\approx 0.9^{26}$. Consequently, the accuracy of estimates of fat and carbohydrate oxidation provided by indirect calorimetry is likely to decline as the RER approaches 1.0. Values are probably reliable at lower work intensities, but the intensity, or RER, at which the inaccuracy becomes important has not been determined in horses.

The regulation of endogenous fat and carbohydrate metabolism in relation to exercise intensity has not been formally investigated in horses. However, a similar trend is observed of increasing contribution from carbohydrate oxidation and decreasing contribution from fat oxidation, as a $\%$ of the energy used to fuel exercise, with increasing exercise intensity if we compare two studies: (1) horses exercised at $35 \% \dot{\mathrm{VO}}_{2 \max }$ for $90 \mathrm{~min}$ have an energy expenditure of $\approx 210 \mathrm{cal} \mathrm{kg}^{-1}$ $\min ^{-1}$ with relative contributions to energy of $\approx 42 \%$ from fat oxidation and $\approx 58 \%$ from carbohydrate ${ }^{27}$; and (2) horses exercised at $50 \% \dot{\mathrm{VO}}_{2 \max }$ for $60 \mathrm{~min}$ have an energy expenditure of $\approx 325 \mathrm{cal} \mathrm{kg}^{-1} \mathrm{~min}^{-1}$ with relative contributions to energy of $\approx 30 \%$ from fat oxidation and $\approx 70 \%$ from carbohydrate ${ }^{28}$. In addition, at the same exercise intensity the pattern of substrate oxidation is dependent on duration of exercise. In horses exercised at $35 \% \quad \dot{\mathrm{VO}} \mathrm{Lmax}_{\max }$ for
$90 \mathrm{~min}$, during the $0-30,30-60$ and 60-90 minute intervals, fat oxidation accounts for $\approx 43 \%, \approx 55 \%$ and $\approx 68 \%$, and carbohydrate oxidation accounts for $\approx 57 \%, \approx 45 \%$ and $\approx 32 \%{ }^{27}$. Therefore, there is a shift in the contribution to energy expenditure from carbohydrate to fat oxidation as duration of an exercise bout increases.

\section{Carbohydrate metabolism: muscle glycogen, liver glycogen and plasma glucose}

The fuel reserves of a horse are in the form of fat, carbohydrates and protein. Protein is a quantitatively important source of energy production only in starvation. Since fats are more energy-dense and the amount of fat reserves is greater, horses have as much as 20-25 times more energy stored in the form of fat than carbohydrate ${ }^{29}$ (Table 1). Therefore, similar to other species, carbohydrate stores of horses are relatively limited when compared to fat. In addition, exercise performed by horses in athletic events requires concurrent oxidation of carbohydrate and fat. For these reasons carbohydrate availability and oxidation by working skeletal muscle may become a limiting factor for exercise performance. The impact of carbohydrate availability and oxidation on exercise performance has been demonstrated in horses in two situations: (1) as an increase in the time to fatigue in horses administered supplemental glucose by intravenous infusion during moderateintensity exercise $\mathrm{e}^{30}$, and (2) by depletion of muscle glycogen prior to exercise and demonstration of subsequent lower exercise performance ${ }^{31,32}$. These studies are discussed below in greater detail.

Carbohydrates are either absorbed from the gastrointestinal tract or synthesized de novo by liver gluconeogenesis. Carbohydrates are stored in the body in the form of glycogen. Other forms of carbohydrate that contribute to energy supply during exercise are plasma glucose and lactate. The rest of the carbohydrates in the body are mostly in the form of glycosylated proteins or lipids and are not quantitatively relevant to exercise metabolism.

Liver glycogen is used to maintain normal glucose concentrations in periods when glucose availability from intestinal absorption is decreased. Those tissues dependent solely on glucose for their metabolism, such as neurons and red blood cells, require a constant supply of glucose from the liver via breakdown of glucose from glycogen or synthesis of glucose from gluconeogenic precursors, such as lactate, glycerol and most amino acids. Propionate, which is one of the VFAs absorbed in the hindgut from microbial fermentation of plant fibre, is considered a very important gluconeogenic precursor in resting horses, 
and it may account for as much as $50-60 \%$ of hepatic glucose production in non-exercising horses ${ }^{33}$.

Unlike liver glycogen, muscle glycogen does not contribute to maintenance of normoglycaemia. The majority of muscle glycogen is stored in fast-twitch high oxidative (Type-IIA) and fast-twitch low oxidative (Type-IIB) muscle fibres. These muscle fibre types are those most dependent on glycogen for synthesis of ATP via oxidative phosphorylation and/or glycolysis resulting in lactic acid formation. Glycogen granules are particles of carbohydrate with complexed proteins (glycogenin, glycogen synthase, glycogen phosphorylase and phosphorylase kinase) found in subsarcolemmal and myofibrillar locations. In the vastus lateralis of humans, most of the glycogen granules are found between myofibrils, but the subsarcolemmal space is also densely packed with glycogen granules ${ }^{34}$.

\section{Glucose metabolism during exercise in horses}

\section{Plasma glucose concentrations and glucose kinetics during exercise}

In horses, unlike humans and dogs, plasma glucose concentrations increase $\left(2-4 \mathrm{mM}, 36-72 \mathrm{mg} \mathrm{dl}^{-1}\right)$ even during moderate-intensity exercise $\left(\begin{array}{lll}50 \% & \dot{\mathrm{VO}}_{2 \max }\end{array}\right)^{30}$. This indicates a mismatch between the rate of appearance of glucose in blood (glucose $R_{a}$ ) and the rate of disappearance of glucose from blood (glucose $R_{d}$ ). Using stable isotope techniques it has been determined in horses that both glucose $\mathbf{R}_{\mathbf{a}}$ (hepatic glucose production) and $R_{d}$ (net glucose disposal by peripheral tissues) increase four-fold during exercise at $35 \% \dot{\mathrm{VO}}_{2 \max }$ compared with resting values ${ }^{27}$. However at $50 \%$ $\dot{\mathrm{V}} \mathrm{O}_{2 \max }$ glucose $\mathrm{R}_{\mathrm{a}}$ increases seven-fold but glucose $\mathrm{R}_{\mathrm{d}}$ increases by only four-fold compared with resting values $^{35}$. This mismatch in the glucose turnover rates may be partly or completely due to sympathoadrenergic mechanisms operating directly via hepatic sympathetic innervation or indirectly via circulating adrenaline, as discussed below.

\section{Insulin, glucagon and insulin:glucagon ratio during exercise}

Insulin and glucagon act to maintain glucose homeostasis and prevent hypoglycaemia despite large increases in glucose uptake by working skeletal muscle. Similar to other species, during low- and moderate-intensity exercise plasma insulin concentration of horses decreases, plasma glucagon concentration increases and the insulin:glucagon ratio decreases ${ }^{23,27}$. However, these responses will be altered if plasma glucose concentrations are elevated by oral or intravenous glucose administration. Plasma insulin concentration during exercise is higher, and plasma glucagon is lower, when plasma glucose concentration is high during exercise because of administration of glucose before or during exercise in horses ${ }^{27,35}$.

\section{Catecholamines and glucose turnover rates}

Sympathoadrenergic mechanisms play an important role in the control of plasma glucose concentrations during exercise. The mismatch between glucose production and glucose oxidation during moderate-intensity exercise leads to hyperglycaemia in horses. An excessive rate of hepatic glucose production and lower rate of peripheral glucose disposal partly account for this phenomenon, as evidenced by $\beta$-adrenergic blockade by the non-selective $\beta$-blocker propranolol augmenting, and adrenaline infusion inhibiting, the rate of glucose disposal by skeletal muscle ${ }^{23,35}$.

\section{Effect of training status on glucose kinetics in borses}

In humans, training results in a lower rate of glucose oxidation during exercise at the same absolute intensity when compared with pretraining values ${ }^{36}$. Similarly, training decreases reliance on glycogenolysis and blood-borne glucose oxidation during exercise in horses when compared with the response before training at the same absolute, but not relative, exercise intensity ${ }^{37}$.

\section{Glucose availability and exercise performance in horses}

Blood glucose is an important fuel for contracting muscle. Studies in human subjects have demonstrated that over $90 \%$ of the whole-body glucose uptake during moderate-intensity exercise is oxidized by skeletal muscle ${ }^{36}$. Increased glucose availability during prolonged moderate-intensity exercise by ingestion of glucose, glucose polymers, sugar-rich snacks or carbohydrate meals prior to and/or during exercise in humans enhances performance, measured as an increased time to fatigue or an improvement in time to complete a set distance ${ }^{38}$. Similarly, the time to fatigue is prolonged by $14-20 \%$ in horses exercised to exhaustion at $50-60 \% \dot{\mathrm{V}} \mathrm{O}_{2 \max }$, when plasma glucose availability is enhanced by intravenous administration of glucose $\mathrm{e}^{30,39}$. However, the relative contribution to energy expenditure from blood-borne glucose oxidation during exercise in horses is modest at best when compared with oxidation of muscle glycogen and intra/extramuscular sources of fat. At exercise intensities varying from $30-60 \%$ of $\mathrm{VO}_{2 \max }$ muscle glycogen oxidation and fat oxidation account for 32-68\% and $25-56 \%$ respectively of the energy expenditure, whereas oxidation of blood-borne glucose accounts for only $6-12 \%$ of the energy expenditure during exercise $^{23,27,28}$. 
Increased glucose availability by intragastric administration of a glucose solution $\left(2 \mathrm{~g} \mathrm{~kg}^{-1}\right)$ prior to exercise increases the rate of blood-borne glucose oxidation and the rate of whole body carbohydrate oxidation but muscle glycogenolysis is unchanged ${ }^{35}$. However, the effect of increased glucose availability by oral/intragastric administration on exercise performance in horses has not been determined.

Intravenous or oral glucose administration is not a practical intervention in athletic field events. A more practical strategy to increase glucose availability prior to exercise is to provide a starch-rich meal, such as corn or oats, prior to exercise in order to increase plasma glucose availability by intestinal digestion and absorption of glucose. Increasing glucose availability prior to exercise in horses by providing a grain meal does alter carbohydrate and fat metabolism but the effect of such a meal prior to exercise on athletic performance has not been determined in horses ${ }^{28}$.

\section{Muscle glycogen and exercise performance in horses}

\section{Muscle glycogen depletion and rates of muscle glycogenolysis in exercising borses}

The normal glycogen concentration in the horse's muscle is $130-140 \mathrm{mmol} \mathrm{kg}^{-1} \mathrm{ww} \quad(560-600 \mathrm{mmol}$ $\mathrm{kg}^{-1} \mathrm{dw}$ ), which is greater than the values in human athletes of $80-100 \mathrm{mmol} \mathrm{kg}{ }^{-1} \mathrm{ww} \quad(340-425 \mathrm{mmol}$ $\left.\mathrm{kg}^{-1} \mathrm{dw}\right)^{40-43}$. This greater concentration of muscle glycogen may contribute to the greater athletic capacity of horses. However, despite this greater concentration muscle glycogen concentrations are substantially depleted by exercise.

During a competitive 50 to $100 \mathrm{~km}$ endurance ride $(\approx 4-9 \mathrm{~h}$ events) muscle glycogen depletion was found to be $57-65 \%$ and the rate of muscle glycogenolysis during these events was $0.14-0.30 \mathrm{mmol} \mathrm{kg}^{-1}$ ww $\min ^{-1}$ (refs 4 and 5 ). In a simulated $80 \mathrm{~km}$ endurance ride that lasted $4 \mathrm{~h}$ muscle glycogen depletion was found to be greater than $90 \%$ and the average rate of muscle glycogenolysis was $0.5 \mathrm{mmol} \mathrm{kg}-1$ ww $\min ^{-1}$ (ref. 43). Therefore, substantial muscle glycogen depletion is observed in horses performing long distance, low- to moderate-intensity exercise. During prolonged exercise glycogen depletion in different muscle fibre types occurs progressively, with initial depletion occurring in Type-I fibres and depletion of glycogen in Type-IIB fibres occurring later. This pattern of depletion is related to progressive recruitment of muscle fibre types ${ }^{5,44}$.

High-intensity exercise results in exponential increases in the rate of muscle glycogenolysis in humans. Similarly, in horses running an $800 \mathrm{~m}$ sprint (14.3 $\mathrm{m} \mathrm{s}^{-1}, 32 \mathrm{mph}$ for 50-60 s) or a $2000 \mathrm{~m}$ sprint $\left(13.4 \mathrm{~m} \mathrm{~s}^{-1}, 30 \mathrm{mph}\right.$ for $\left.2.5 \mathrm{~min}\right)$ the rates of muscle glycogenolysis were found to be $37 \mathrm{mmol} \mathrm{kg}^{-1}$. Ww min ${ }^{-1}$ and $16 \mathrm{mmol} \mathrm{kg}^{-1} \mathrm{ww} \mathrm{min}^{-1}$, respectively $^{42}$. Muscle glycogen depletion at these exercise intensities varies from $20 \%$ to $40 \%$ of values before exercise $^{42,45-47}$. The pattern of glycogen depletion during high-intensity exercise in Thoroughbred and Standardbred races shows that significant glycogen depletion occurs in Type-IIA and -IIB muscle fibres $^{3,44}$. These estimates of muscle glycogenolysis should approximate to the rates of glycogen utilization in competitive Thoroughbred or Standardbred races.

The differences observed between humans and horses in resting muscle glycogen concentration, rate of muscle glycogenolysis during exercise and rate of muscle glycogen synthesis after exercise may be partly explained by differences in muscle fibre composition. The vastus lateralis muscle of human marathon runners has up to $80 \%$ of Type-I fibres, while that of elite sprinters contains up to $60 \%$ of the Type-II fasttwitch fibres ${ }^{48,49}$. In contrast, muscle fibre type composition in the gluteus medius muscle of horses is not nearly as variable as in humans. Horses competing in endurance events have 18-32\% Type-I, 36-46\% Type-IIA and 20-38\% Type-IIB muscle fibres in their gluteus medius ${ }^{2,4,5}$, whereas Thoroughbred racehorses have 7-11\% Type-I, 57-61\% Type-IIA and 28-32\% Type-IIB in their gluteus medius muscle ${ }^{50}$. Therefore, the high muscle glycogen concentration, fast rate of glycogenolysis during exercise and slow rates of muscle glycogen synthesis after exercise observed in horses when compared with humans may be partly related to a lower percentage of slowtwitch Type-I muscle fibres in major locomotory muscles.

\section{Exercise performance and muscle glycogen}

In human athletes low muscle glycogen concentrations before exercise are associated with decreased exercise performance and conversely, high muscle glycogen concentrations enhance performance ${ }^{40}$. Increased muscle glycogen availability prior to exercise has been shown to enhance endurance exercise performance in humans ${ }^{38,51}$, and it is common practice in cyclists and marathon runners to reduce training and increase carbohydrate intake during the days prior to a competitive event. However, each gram of glycogen is stored with $\approx 2.7 \mathrm{~g}$ of water, and glycogen loading may result in a weight gain, which may be detrimental for high-intensity exercise.

The relationship between muscle glycogen and exercise performance has not been investigated as extensively in horses. However, low muscle glycogen concentrations prior to exercise in horses appear to decrease exercise performance at moderate- and high-intensity exercise. Time to exhaustion in horses trotting at $6.5 \mathrm{mph}\left(3 \mathrm{~m} \mathrm{~s}^{-1}\right)$ decreases by $35 \%$ when 
muscle glycogen prior to exercise is $70 \%$ lower than normal $^{52}$. Anaerobic work performance, as measured by pulling increasing weight loads on a sled, decreases by $31 \%$ in horses when muscle glycogen is $42 \%$ lower than normal ${ }^{53}$. Anaerobic work performance tests are designed to estimate the capacity to perform brief maximal-intensity exercise that relies mostly on utilization of the intramuscular ATP-phosphocreatine pool and anaerobic glycolysis to fuel work during high-intensity exercise. In a different study under controlled laboratory conditions, horses undergoing three consecutive days of aerobic intense exercise followed by $1 \mathrm{~min}$ sprints had a depletion of muscle glycogen of $55-75 \%{ }^{31,32}$. When muscle glycogen remained decreased by $60 \%$, maximum accumulated oxygen deficit, which is another estimate of anaerobic capacity, and run time to fatigue during an 'all out' sprint of $2 \mathrm{~min}$ at $25 \mathrm{mph}$, decreased by $26 \%$ and $28 \%$ respectively ${ }^{32}$.

In summary, exercise- and dietary-induced muscle glycogen depletion is associated with decreased exercise performance both at low- and high-intensity exercise in horses. However, attempts to increase muscle glycogen concentration above that usually found have proved unfruitful and the effect of high muscle glycogen concentrations on exercise performance in horses is unknown.

\section{Muscle glycogen syntbesis}

Muscle glycogen synthesis after exercise will depend on substrate availability and interval from completion of the exercise bout to delivery of substrate. Muscle glycogen replenishment is enhanced in horses when supplemental glucose is administered as an intravenous infusion $\left(6 \mathrm{~g} \mathrm{~kg}^{-1}\right)^{54}$. However, intragastric administration of an oral glucose polymer at $3 \mathrm{~g} \mathrm{~kg}^{-1}$ does not enhance muscle glycogen synthesis in horses ${ }^{55}$, unlike ingestion of the same amount of glucose in humans. In these studies, by $24 \mathrm{~h}$ after exercise muscle glycogen did not return to concentrations found prior to exercise, even for those horses administered supplemental oral or intravenous glucose $\mathrm{e}^{54,55}$. In contrast, humans with similar degrees of glycogen depletion have replenished or even supercompensated muscle glycogen stores by $24 \mathrm{~h}$ when glucose is ingested as a solution or as meals with a high glycaemic index.

In Thoroughbreds and trotting Standardbreds, the rate of muscle glycogen synthesis after high-intensity sprinting exercise, which lowers muscle glycogen concentration by $30-40 \%$, varies between 0.6 and $1.5 \mathrm{mmol} \mathrm{kg}^{-1} \mathrm{ww} \mathrm{h}^{-1}$ (refs 46, 47 and 56). Unlike other animals, horses fed increasing amounts of digestible carbohydrate have only a minimal increase in the rate of muscle glycogen synthesis ${ }^{57}$, and the rate of glycogen synthesis after high-intensity sprint exercise is $\approx 1.5 \mathrm{mmol} \mathrm{kg}^{-1} \mathrm{ww} \mathrm{h}^{-1}$ (ref. 46) which is four times lower than values observed in human athletes ${ }^{58,59}$. In a controlled laboratory study, horses which had undergone three consecutive days of aerobic intense exercise followed by $1 \mathrm{~min}$ sprints had a depletion of muscle glycogen of $55-75 \%{ }^{31}$ and were subsequently fed one of three isocaloric diets containing increasing amounts of soluble carbohydrates for 3 days $^{57}$. For those horses fed a diet high in grain and low in roughage, the rate of muscle glycogen synthesis was higher and replenishment was complete by 3 days, whereas those horses fed a mixed hay and grain diet, or mostly hay, did not attain complete replenishment of muscle glycogen. The rate of muscle glycogen synthesis was $\approx 1.5 \mathrm{mmol} \mathrm{kg}^{-1} \mathrm{ww} \mathrm{h}^{-1}$ (ref. 57). Therefore, muscle glycogen synthesis in horses is complete in 3 days when the diet fed after exercise contains sufficient starch. However, long-term feeding of such a high proportion of starch may not be well tolerated by horses.

The reasons for the relatively slower rate of muscle glycogen replenishment after exercise in horses, when compared with other species, have not been elucidated. One possibility, as discussed below, is that the gastrointestinal function of the horse is not well suited to digest starch and other soluble carbohydrates that will be a source of glucose for glycogen replenishment. If this is the case, the limiting factor is glucose availability from the gastrointestinal tract. This possibility is supported by the fact that intravenous glucose supplementation enhances muscle glycogen synthesis in horses after exercise, whereas oral glucose polymer administration does not ${ }^{54,55}$. A second possibility is that those molecular mechanisms involved in insulinstimulated glycogen synthesis are not as functional as in other species. Two of the mechanisms involved in glycogen synthesis are: (1) the insulin-stimulated translocation of glucose transporters (glucose transporter type 4) from intracellular vesicle pools to the sarcolemma, and (2) the activity of glycogen synthase. The molecular mechanisms underlying glycogen synthesis in horses are an active area of research but there are no published studies at this point in time.

\section{Nutritional interventions to alter/optimize carbohydrate metabolism during exercise in horses}

\section{Effect of meal type prior to exercise on carbobydrate metabolism during exercise}

Studies performed in horses have described the effects of different meal types prior to exercise on a number of plasma substrates and hormones during and after moderate-intensity exercise ${ }^{60-66}$. In summary, ingestion of a high-glycaemic meal, such as corn, $2-4 \mathrm{~h}$ prior to a moderate-intensity exercise bout results in transient decrease in plasma glucose concentration 
during exercise, attenuation of exercise-induced increase of NEFA concentration and increased serum insulin concentration during exercise when compared with horses not fed or fed a hay meal. These alterations in plasma and serum concentrations of substrates and hormones have been hypothesized to be deleterious for performance in horses, presumably because they lead to impaired substrate use during exercise. However, a complete quantitative analysis by indirect calorimetry and stable isotopic tracer methods of the effects of meal type prior to exercise on substrate metabolism has not been conducted until recently ${ }^{28}$. Horses fed a corn meal an hour prior to exercise at $50 \% \mathrm{~V}_{2 \max }$ for $60 \mathrm{~min}$ have greater rates of bloodborne glucose oxidation and whole-body carbohydrate oxidation when compared with those eating an isocaloric meal of hay or those from which food has been withheld; however, ingestion of a meal of corn had no sparing effect on muscle glycogen utilization ${ }^{28}$. In addition, neither the latter nor previous studies have determined the effect of meal type, or of withholding feed prior to exercise, on athletic performance.

\section{Dietary manipulations intended to minimize muscle glycogenolysis during exercise and/or optimize muscle glycogen syntbesis after exercise}

Horses fed a fat-supplemented diet $(10 \%$ of fat as weight) for 3 weeks have greater muscle glycogen concentration prior to exercise and greater muscle glycogenolysis during sprinting exercise when compared with those fed a control diet of hay and grain ${ }^{67}$. However, the diets fed in this study appear not to be isocaloric. In a study in which horses were fed a diet of $15 \%$ added-fat, when compared to no-fat feeding (diets were not isocaloric), muscle glycogen concentration was lower before and after exercise and net muscle glycogenolysis was not different ${ }^{68}$. In another study in which horses were fed isocaloric diets after exercise, one of the two diets containing 5\% of fat, muscle glycogen synthesis was not different ${ }^{69}$. In summary, some authors claim that feeding horses a high-fat diet has a muscle glycogen-sparing effect or increases muscle glycogen concentration; however the evidence is conflicting, partly due to differences in study design, and further study is required.

One of the causes of the horse's limited ability to digest starch in grains may be its low rate of amylase secretion. Amylase is the enzyme, released by the pancreas, responsible for degradation of starch. The output of amylase per unit weight of pancreatic tissue in horses is only 5-6\% that of pigs, therefore the amount of starch horses can tolerate is relatively small compared with other monogastric animals ${ }^{70,71}$. Similarly, horses, when compared with cattle, have a pancreatic flow that is three times higher but amylase concentration in pancreatic secretion is $1 / 10$ of that in cattle $\mathrm{f}^{72,73}$. Therefore, the horse's ability to secrete amylase into the small intestine is lower than in other herbivores or other monogastric animals. The maximal starch ingestion tolerated by horses is $0.3-0.4 \%$ of body weight; in other words a $450-\mathrm{kg}$ horse $(\approx 1000 \mathrm{lb})$ has a maximal starch digestibility of $1.4-1.8 \mathrm{~kg}(3-4 \mathrm{lb})$ of starch, which is equal to $2.3-3 \mathrm{~kg}(5-6.7 \mathrm{lb})$ of $\operatorname{corn}^{74}$.

As described previously under 'Muscle glycogen synthesis', horses that undergo three consecutive days of muscle glycogen-depleting exercise will have an enhanced rate of muscle glycogen synthesis when fed a diet high in starch. In order to avoid the gastrointestinal complications of feeding excessive amounts of grain to horses, one possibility is to increase the number of feedings per day and decrease the amount of each meal. In doing so, one would minimize the risks of diets high in grain intake without compromising even further muscle glycogen synthesis.

In summary: (1) energy metabolism of horses during exercise is different to that of humans and dogs, therefore data obtained in other athletic species should not be directly extrapolated; (2) carbohydrate availability may limit performance in horses as demonstrated by decreased exercise performance when muscle glycogen concentrations are low, as well as by increased exercise performance when glucose is supplemented intravenously; and (3) horses have a limited capacity for rapid muscle glycogen synthesis when compared with other species, which may be related to differences in diets and in adaptations of the gastrointestinal tract.

\section{References}

1 Lewis LD (1995). Equine Clinical Nutrition: feeding and care. Baltimore, MD: William and Wilkins, pp. 3-24.

2 Hodgson DR, Rose RJ and Allen JR (1983). Muscle glycogen depletion and repletion patterns in horses performing various distances of endurance exercise. In: Snow D, Persson SGB and Rose RJ (eds) Equine Exercise Physiology. Cambridge, UK: Granta Editions, pp. 229-236.

3 Hodgson DR, Rose RJ, Allen JR and Dimauro J (1984). Glycogen depletion patterns in horses performing maximal exercise. Research in Veterinary Science 36: 169-173.

4 Essén-Gustavsson B, Karlström K and Lindholm A (1984). Fibre types, enzyme activities and substrate utilization in skeletal muscles of horses competing in endurance rides. Equine Veterinary Journal 16(3): 197-202.

5 Snow DH, Baxter P and Rose RJ (1981). Muscle fibre composition and glycogen depletion in horses competing in an endurance ride. Veterinary Record 108: 374-378.

6 Rivero JLL, Talmadge RJ and Edgerton VR (1996). Correlation between myofibrillar ATPase activity and myosin heavy chain composition in equine skeletal muscle and the influence of training. The Anatomical Record 246: 195-207.

7 Quiroz-Rothe E and Rivero JLL (2001). Co-ordinated expression of contractile and non-contractile features of control equine muscle fibre types characterised by 
immunostaining of myosin heavy chains. Histocbemistry and Cell Biology 116: 299-312.

8 Romijn JA, Coyle EF, Sidossis LS, Zhang XJ and Wolfe RR (1995). Relationship between fatty acid delivery and fatty acid oxidation during strenuous exercise. Journal of Applied Pbysiology 79(6): 1939-1945.

9 Starritt EC, Howlett RA, Heigenhauser GJ and Spriet LL (2000). Sensitivity of CPT I to malonyl-CoA in trained and untrained human skeletal muscle. American Journal of Pbysiology (Endocrinology and Metabolism) 278(3): E462 - E468.

10 Richter E, Ruderman NB, Gavras H, Belur ER and Galbo H (1982). Muscle glycogenolysis during exercise: dual control by epinephrine and contractions. American Journal of Physiology 242: E25-E32.

11 Romijn JA, Coyle EF, Sidossis LS, Gastaldelli A, Horowitz JF, Endert E, et al. (1993). Regulation of endogenous fat and carbohydrate metabolism in relation to exercise intensity and duration. American Journal of Pbysiology (Endocrinology Metabolism) 265: E380-E391.

12 Romijn JA, Coyle EF, Sidossis LS, Rosenblatt J and Wolfe RR (2000). Substrate metabolism during different exercise intensities in endurance-trained women. Journal of Applied Physiology 88: 1707-1714.

13 Rose RJ, Hodgson DR, Kelso TB, McCurcheon LJ, Reid TA, Bayley WM, et al. (1988). Maximum $\mathrm{O}_{2}$ uptake, $\mathrm{O}_{2}$ debt and deficit, and muscle metabolites in Thoroughbred horses. Journal of Applied Pbysiology 64(2): 781 - 788.

14 Saltin B and Åstrand PO (1967). Maximal oxygen consumption in athletes. Journal of Applied Pbysiology 23(3): $353-358$.

15 Seeherman HJ and Morris EA (1990). Methodology and repeatability of a standardised treadmill exercise test for clinical evaluation of fitness in horses. Equine Veterinary Journal Supplement (9): 20-25.

16 Lindstedt SL, Hokanson JF, Wells DJ, Swain SD, Hoppeler H and Navarro V (1991). Running energetics in the pronghorn antelope. Nature 353(6346): 748-750.

17 Wagner PD (1995). Determinants of $\mathrm{Vo}_{2 \max }$ : man vs horse. Journal of Equine Veterinary Sciences 15(9): 398-404.

18 Boileau RA and Horswill CA (2000). Body composition in sports: measurement and applications for weight loss and gain. In: Garrett WE, and Kirkendall DT (eds) Exercise and Sport Science. Philadelphia, PA: Lippincott Williams and Wilkins, pp. 319-338.

19 Gunn HM (1987). Muscle, bone and fat proportions and muscle distribution of Thoroughbreds and other horses. In: Gillespie JR, and Robinson NE (eds) Equine Exercise Pbysiology. Davis, CA: ICEEP Publications, pp. 253-264.

20 Hoppeler H, Jones JH, Lindstedt SL, Claassen H, Longworth KE, Taylor CR, et al. (1987). Relating maximal oxygen consumption to skeletal muscle mitochondria in horses. In: Gillespie JR, and Robinson NE (eds) Equine Exercise Physiology 2. Davis, CA: ICEEP Publications, pp. 278-289.

21 Hoppeler H (1985). Muscle aerobic potential in the animal kingdom. In: Saltin B (ed.) Biochemistry of Exercise VI, International Series on Sport Sciences. Champaign, IL: Human Kinetics Publishers, pp. 417-434.

22 Roberts TJ, Weber JM, Hoppeler H, Weibel ER and Taylor CR (1996). Design of the oxygen and substrate pathways II. Defining the upper limits of carbohydrate and fat oxidation. Journal of Experimental Biology 199: 1651 - 1658.

23 Geor RJ, Hinchcliff KW and Sams RA (2000). $\beta$-Adrenergic blockade augments glucose utilization in horses during graded exercise. Journal of Applied Pbysiology 89: 1086- 1098.

24 Davie AJ, Evans DL, Hodgson DR and Rose RJ (1999). Effects of muscle glycogen depletion on some metabolic and physiological responses to submaximal treadmill exercise. Canadian Journal of Veterinary Research 63: 241 - 247.
25 Eaton MD, Evans DL, Hodgson DR and Rose RJ (1995). Effect of treadmill incline and speed on metabolic rate during exercise in Thoroughbred horses. Journal of Applied Pbysiology 79(3): $951-957$.

26 Romijn JA, Coyle EF, Hibbert J and Wolfe RR (1992). Comparison of indirect calorimetry and a new breath ${ }^{13} \mathrm{C} /{ }^{12} \mathrm{C}$ ratio method during strenuous exercise. American Journal of Physiology (Endocrinology and Metabolism) 263: E64-E71.

27 Geor RJ, Hinchcliff KW and Sams RA (2000). Glucose infusion attenuates endogenous glucose production and enhances glucose use of horses during exercise. Journal of Applied Physiology 88: 1765-1776.

28 Jose-Cunilleras E, Hinchcliff KW, Sams RA, Devor ST and Linderman JK (2002). Glycemic index of a meal fed before exercise alters substrate use and glucose flux in exercising horses. Journal of Applied Pbysiology 92: 117-128.

29 Harris P (1997). Energy sources and requirements of the exercising horse. Annual Review of Nutrition 17: 185-210.

30 Farris JW, Hinchcliff KW, McKeever KH and Lamb DR (1995). Glucose infusion increases maximal duration of prolonged treadmill exercise in Standardbred horses. Equine Veterinary Journal Supplement (18): 357-361.

31 Lacombe V, Hinchcliff KW, Geor RJ and Lauderdale MA (1999). Exercise that induced substantial muscle glycogen depletion impairs subsequent anaerobic capacity. Equine Veterinary Journal Supplement (30): 293-297.

32 Lacombe VA, Hinchcliff KW, Geor RJ and Baskin CR (2001). Muscle glycogen depletion and subsequent replenishment affect anaerobic capacity of horses. Journal of Applied Pbysiology 91: 1782-1790.

33 Simmons HA and Ford EJH (1991). Gluconeogenesis from propionate produced in the colon of the horse. British Veterinary Journal 147(4): 340-345.

34 Marchand I, Chorneyko K, Tarnopolsky M, Hamilton S, Shearer J, Potvin J, et al. (2002). Quantification of subcellular glycogen in resting human muscle: granule size, number, and location. Journal of Applied Physiology 93: 1598-1607.

35 Geor RJ, Hinchcliff KW, McCutcheon LJ and Sams RA (2000). Epinephrine inhibits exogenous glucose utilization in exercising horses. Journal of Applied Pbysiology 88 : $1777-1790$.

36 Coggan AR, Kohrt WM, Spina RJ, Bier DM and Holloszy JO (1990). Endurance training decreases plasma glucose turnover and oxidation during moderate-intensity exercise in men. Journal of Applied Physiology 68: 990-996.

37 Geor RJ, McCutcheon LJ, Hinchcliff KW and Sams RA (2002). Training-induced alterations in glucose metabolism during moderate-intensity exercise. Equine Veterinary Journal Supplement (34): $22-28$.

38 Jacobs KA and Sherman WM (1999). The efficacy of carbohydrate supplementation and chronic high-carbohydrate diets for improving endurance performance. International Journal of Sport Nutrition 9: 92-115.

39 Farris JW, Hinchcliff KW, McKeever KH, Lamb DR and Thompson DL (1998). Effect of tryptophan and of glucose on exercise capacity of horses. Journal of Applied Physiology 85: 807-816.

40 Bergström J, Hermansen L, Hultman E and Saltin B (1967). Diet, muscle glycogen, and physical performance. Acta Pbysiologica Scandinavica 71: 140-150.

41 Essén-Gustavsson B, McMiken D, Karlström K, Lindholm A and Persson SGB (1989). Muscular adaptation of horses during intensive training and detraining. Equine Veterinary Journal 21(1): $27-33$.

42 Harris RC, Marlin DJ and Snow DH (1987). Metabolic response to maximal exercise of 800 and $2000 \mathrm{~m}$ in the Thoroughbred horse. Journal of Applied Pbysiology 63(1): $12-19$.

43 Snow DH, Kerr MG, Nimmo MA and Abbott EM (1982). 
Alterations in blood, sweat, urine and muscle composition during prolonged exercise in the horse. Veterinary Record 110: 377 - 384

44 Valberg $S$ (1986). Glycogen depletion patterns in the muscle of Standardbred trotters after exercise of varying intensities and durations. Equine Veterinary Journal 18(6): 479-484.

45 Nimmo MA and Snow SH (1983). Changes in muscle glycogen, lactate and pyruvate concentrations in the Thor oughbred horse following maximal exercise. In: Snow DH, Persson SGB, and Rose RJ (eds) Equine Exercise Pbysiology. Cambridge, UK: Granta Editions, pp. 237-244.

46 Snow DH, Harris RC, Harman JC and Marlin DJ (1987). Glycogen repletion following different diets. In: Gillespie JR and Robinson NE (eds) Equine Exercise Pbysiology 2. Davis, CA: ICEEP Publications, pp. 701-706.

47 Snow DH and Harris RC (1991). Effects of daily exercise on muscle glycogen in the Thoroughbred horse. In: Persson SGB, Lindholm A and Davis LBJ (eds). Equine Exercise Physiology 3: Proceedings of the Third International Conference on Exercise Pbysiology, Uppsala, Sweden, 15-19 July 1990. Davis, CA: ICEEP Publications, pp. 299-304.

48 Komi PV and Karlsson J (1978). Skeletal muscle fibre types, enzyme activities and physical performance in young males and females. Acta Pbysiologica Scandinavica 103(2): 210-218.

49 Bergh U, Thorstensson A, Sjodin B, Hulten B, Piehl K and Karlsson J (1978). Maximal oxygen uptake and muscle fiber types in trained and untrained humans. Medicine and Science in Sports 10(3): 151-154.

50 Snow DH and Guy PS (1981). Fibre type and enzyme activities of the gluteus medius in different breeds of horse. In: Poortmans J, and Niset G (eds) Biochemistry of Exercise IVB. Baltimore, MD: University Park Press, pp. 275-282.

51 Hawley JA, Schabort EJ, Noakes TD and Dennis SC (1997). Carbohydrate-loading and exercise performance. An update. Sports Medicine 24(2): 73-81.

52 Topliff DR, Potter GD, Dutson TR, Kreider JL and Jessup GT (1983). Diet manipulation and muscle glycogen in the equine. In: Proceedings of the 8th Equine Nutrition and Physiology Symposium. Savoy, IL: Equine Nutrition and Physiology Society, pp. 119-124.

53 Topliff DR, Potter GD, Kreider JL, Dutson TR and Jessup GT (1985). Diet manipulation, muscle glycogen metabolism and anaerobic work performance in the equine. In: Proceedings of the 9th Equine Nutrition and Physiology Symposium. Savoy, IL: Equine Nutrition and Physiology Society, pp. 224-229.

54 Davie AJ, Evans DL, Hodgson DR and Rose RJ (1995). Effects of intravenous dextrose infusion on muscle glycogen resynthesis after intense exercise. Equine Veterinary Journal 18: 195-198.

55 Davie AJ, Evans DL, Hodgson DR and Rose RJ (1994). The effects of an oral glucose polymer on muscle glycogen resynthesis in Standardbred horses. Journal of Nutrition 124: 2740 - 2741S

56 Hyyppä S, Räsänen LA and Pösö AR (1997). Resynthesis of glycogen in skeletal muscle from Standardbred trotters after repeated bouts of exercise. American Journal of Veterinary Research 58: $162-166$.

57 Lacombe VA, Hinchcliff KW, Kohn CW and Taylor LE (2002). Post-exercise feeding of meals of varying glycemic index affects muscle glycogen resynthesis in horses. 20th Forum American College of Veterinary Medicine. Journal of Veterinary Internal Medicine 16(3): 336 [abstract 39].

58 Costill DL, Sherman WM, Fink WJ, Maresh C, Witten M and Miller JM (1981). The role of dietary carbohydrates in muscle glycogen resynthesis after strenuous running. American Journal of Clinical Nutrition 34: 1831 - 1836.
59 Ivy JL (1998). Glycogen resynthesis after exercise: effect of carbohydrate intake. International Journal of Sports Medicine 19(Suppl. 2): S142-S145.

60 Essén-Gustavsson B, Blomstrand E, Karlström K, Lindholm $A$ and Persson SGB (1991). Influence of diet on substrate metabolism during exercise. In: Persson SGB, Lindholm A, and Jeffcott LB (eds) Equine Exercise Pbysiology 3. Davis, CA: ICEEP Publications, pp. 288-298.

61 Lawrence L, Soderholm LV, Roberts A, Williams J and Hintz $\mathrm{H}$ (1993). Feeding status affects glucose metabolism in exercising horses. Journal of Nutrition 123: 2152-2157.

62 Lawrence LM, Hintz HF, Soderholm LV, Williams J and Roberts AM (1995). Effect of time of feeding on metabolic response to exercise. Equine Veterinary Journal Supplement (18): 393-395.

63 Pagan JD, Burger I and Jackson SG (1995). The influence of time of feeding on exercise response in Thoroughbreds fed a fat supplemented or high carbohydrate diet. In: Proceedings of the 14th Equine Nutrition and Pbysiology Symposium. Savoy, IL: Equine Nutrition and Physiology Society, pp. $92-93$.

64 Pagan JD and Harris PA (1999). The effects of timing and amount of forage and grain on exercise response in Thoroughbred horses. Equine Veterinary Journal Supplement (30): $451-457$.

65 Rodiek A, Bonvicin S, Stull C and Arana M (1991). Glycemic and endocrine responses to corn or alfalfa fed prior to exercise. In: Persson SGB, Lindholm A, and Jeffcott LB (eds) Equine Exercise Physiology 3. Davis, CA: ICEEP Publications, pp. 323-330.

66 Stull C and Rodiek A (1995). Effects of postprandial interval and feed type on substrate availability during exercise. Equine Veterinary Journal 18: 362-366.

67 Oldham SL, Potter GD, Evans JW, Smith SB, Taylor TS and Barnes WS (1989). Storage and mobilization of muscle glycogen in exercising horses fed a fat-supplemented diet. In: Proceedings of the 11th Equine Nutrition and Pbysiology Symposium. Savoy, IL: Equine Nutrition and Physiology Society, pp. 57-62.

68 Pagan JD, Essén-Gustavsson B, Lindholm A and Thornton J (1987). The effect of dietary energy source on exercise performance in Standardbred horses. In: Gillespie JR, and Robinson NE (eds) Equine Exercise Physiology 2. Davis, CA: ICEEP Publications, pp. 686-700.

69 Hyyppä S, Saastamoinen M and Pösö AR (1999). Effect of a post-exercise fat-supplemented diet on muscle glycogen repletion. Equine Veterinary Journal Supplement (30): 493-498.

70 Alexander F and Chowdhury AK (1958). Enzymes in the ileal juice of the horse. Nature 181: 190.

71 Radicke S, Landes E, Kienzle E and Meyer H (1992). Aktivitat der amylase im Dunndarmchymus in Abhangigkeit von der Futterart [in German, English summary]. In: Proceedings of the 1st European Conference of Horse Nutrition, Hanover, Germany, p. 99.

72 Comline RS, Hall LW, Hickson JCD, Murillo A and Walker RG (1969). Pancreatic secretion in the horse. Journal of Physiology, London 204: 10P-11P.

73 Walker JA, Krehbiel CR and Harmon DL (1994). Effects of slaframine and 4-diphenylacetoxy-N-methylpiperidine methiodidie (4DAMP) on pancreatic exocrine secretion in the bovine. Canadian Journal of Physiology and Pharmacology 72: 39-44.

74 Potter GD, Arnold FF, Householder DD, Hansen GH and Brown KM (1992). Digestion of starch in the small or large intestine of the equine. In: Proceedings of the 1st European Conference of Horse Nutrition, Hanover, Germany, pp. 107-111. 